\title{
INSERÇÃO DA EDUCAÇÃO PROFISSIONAL NOS PROJETOS PEDAGOGICOS DE CURSOS DE LICENCIATURA EM QUÍMICA NOS INSTITUTOS FEDERAIS
}

\author{
Alexandre Geraldo Viana Faria \\ Instituto Federal de Mato Grosso do Sul \\ Maria Celina Piazza Recena \\ Universidade Federal de Mato Grosso do Sul
}

\begin{abstract}
Resumo
Os Institutos Federais foram criados com a obrigatoriedade de ofertar cursos de licenciatura de forma a preparar docentes para atividades na Educação Profissional e Tecnológica (EPT). Para essa oferta, tem-se a necessidade de criação de Projeto Pedagógico de Curso (PPC), que abarca essa modalidade de ensino dentro do cabedal metodológico, pedagógico e teórico da EPT. Analisamos PPCs de Licenciatura em Química para verificar os possíveis enfoques dados à EPT. Nossa abordagem foi qualitativa, os dados foram colhidos por meio da análise documental e enquadrados em categorias: os que não abordam a EPT, os que abordam a EPT de forma explícita e os que abordam a EPT de forma relativa. Os resultados obtidos apontam para a inexistência de enfoques à EPT nos PPC de cursos de Licenciatura em Química, indicando que, se considerarmos os PPCs, os Institutos Federais não estão cumprindo com uma parte dos deveres estabelecidos em lei.
\end{abstract}

Palavras-chave: Educação profissional; projeto pedagógico; licenciatura em química.

\begin{abstract}
The Federal Institutes were created in Brazil with the obligation, provided by law, to offer undergraduate courses in order to prepare qualified teachers to carry out activities in Professional and Technological Education (PTE). For this offer, there is a need for the creation of a Pedagogical Course Project (PCP) that encompasses this teaching modality within the methodological, pedagogical and theoretical framework of PTE. We analyzed PCPs for Chemical Licensing offered at Federal Institutes that were available on the World Wide Web to verify possible approaches to PTE. Our approach was qualitative, with data collected through documentary analysis and classified into three categories: those that do not address PTE, those that address PTE explicitly, and those that address PTE relatively. The results show that PTE has not been approached in the PCP of Chemistry Degree courses offered at the Federal Institutes, indicating that if we consider PCPs, these institutions are not complying with a part of the duties established by law.
\end{abstract}

Keywords: Professional education; pedagogical project; chemistry university graduate.

ISSN 1645-1384 (online) www.curriculosemfronteiras.org 


\section{Introdução}

Anos últimos anos houve considerável aumento na oferta de cursos de Licenciatura em Química, principalmente nos Institutos Federais - IFs, que, por vocação e por força de sua lei de criação, se transformaram em ofertantes de licenciaturas na área de ciências (BRASIL, 2008). Essa questão foi motivada pela escassez de professores de Química e agravada pela necessidade desse profissional ser proficiente, também, na docência do Ensino Técnico dentro dos IFs, que se expandiram rapidamente. Essas instituições, inicialmente Centros Federais, eram formadas por 140 unidades em 2002 e foram transformados nos IFs com 640 campi já em 2016. Porém, será que os profissionais licenciados em Química, que até então estavam sendo formados nas instituições de ensino superior, foram preparados para o exercício da docência no ensino técnico? Essa questão nos motivou a investigar se a formação de professores de Química está articulada com as preocupações teóricas, metodológicas e pedagógicas próprias da Educação Profissional Técnica e Tecnológica - EPT, base da construção dos IFs.

Nossa investigação se concentrou em analisar os Projetos Pedagógicos dos Cursos PPCs como forma de identificar a presença da Educação Profissional em diferentes quesitos desses documentos. Procuramos investigar se os PPCs de Licenciatura em Química nos IFs estão estruturados de forma a abordar a EPT em seus objetivos, no perfil do seu egresso, na existência de componente curricular que aborda a EPT, na quantidade de livros previstos para essas disciplinas e se o estágio supervisionado abarca a EPT.

Como forma de apresentar nossa investigação, esse artigo se estrutura inicialmente apresentando os primórdios da Educação no Brasil com ênfase na Educação Profissional tentando mostrar os acontecimentos cronologicamente, de maneira a demonstrar uma sequência lógica dos fatos envolvendo a EPT. Em nosso texto as apresentações históricas da EPT são desenvolvidas até a criação dos IFs, momento em que nos preocupamos em apresentar as bases legais para a criação dos Institutos e as diferenças desses para com as instituições de ensino até então existentes. Optamos por utilizar nessa pesquisa uma abordagem qualitativa, nos preocupando em descrever os nossos procedimentos metodológicos de forma a evidenciar as articulações entre a coleta dos dados e a análise desses dados. Como os dados colhidos na pesquisa foram obtidos a partir dos textos dos PPCs, procuramos identificar a presença da EPT por meio de alguns termos chaves, "educação profissional"; "ensino técnico", "mercado de trabalho", "mundo do trabalho", "politecnia", "ensino integrado" e "educação integradora". Esse mecanismo foi fundamental para a apresentação de nossos resultados, proporcionando conclusões que permitiram a proposição de indicativos de construção de PPCs de cursos de Licenciatura em Química com atendimento à EPT. 


\section{Educação Profissional no Brasil: do ensino de ofícios aos Centros Federais}

Inicialmente a educação no Brasil ficou, exclusivamente, a cargo dos jesuítas, que se instalaram em nosso território pouco depois da vinda dos portugueses, e mantiveram esse monopólio até a sua expulsão pelo Marquês de Pombal cerca de duzentos anos depois. Somente então, devido a reformas na educação portuguesa, é que se regulamentou o ensino primário e secundário em nosso país e passou-se a permitir que as famílias pudessem buscar o ensino privado em outras ordens religiosas ou até mesmo em outros países. Porém, como política portuguesa para a colônia, fica proibida no território brasileiro a instalação de fábricas, uma vez que o país já reunia, naturalmente, incontáveis vantagens quanto à fertilidade de sua terra e a produção de frutos, e com isso a instalação de fábricas poderia provocar a independência da metrópole (FONSECA, 1961). Já a criação do ensino superior somente ocorreu após a vinda da corte portuguesa, que se instala a partir de 1808, motivada pela nova sociedade que passou a existir. Nesse contexto não se havia considerado o ensino de ofícios, resumindo a educação em nosso país ao ensino primário, responsável em ensinar a ler, escrever e fazer contas; o ensino secundário, que se encarregaria de preparar para $\mathrm{o}$ curso superior; e as faculdades de medicina, agricultura e artes militares que passaram a ser oferecidas na época (MARTINS, 2002).

Como a sociedade brasileira se estabelecia por meio de um sistema em que a execução dos trabalhos manuais era de exclusividade dos escravos, isso fez com que se criasse a ideia de que as atividades artesanais e de manufatura fossem consideradas como trabalho de menor valor. Concepções dessa natureza podem ter contribuído para a tardia implantação de escolas voltadas ao ensino de ofícios, sendo que esse tipo de ensino somente ocorria dentro do próprio ambiente de trabalho, o que era conhecido como escolas-oficinas. A partir de 1840 são criadas as Casas de Educandos Artífices, que se encarregam de recolher jovens e crianças em estado de mendicância, e passam a oferecer o ensino de ofício como forma de aparelhá-los ao trabalho (MANFREDI, 2002).

O início das atividades do primeiro Liceu de Artes e Ofícios do Brasil se dá em 1858 por iniciativa da Sociedade Propagadora das Belas Artes; entidade criada dois anos antes que reunia os mais diversos integrantes da sociedade (BIELINSKI, 2009). Esse liceu, cujo objetivo era promover a formação de mão de obra qualificada em nosso país, existe ainda hoje e possui sede no Rio de Janeiro. A Educação Profissional enquanto política pública surge pela iniciativa do então Presidente do Estado do Rio de Janeiro Nilo Peçanha - equivale ao cargo designado ao governador - que deu início ao ensino técnico por meio do Decreto ${ }^{\circ}$ 787, de 11 de setembro de 1906, que culminou na criação de quatro escolas profissionais naquela unidade federativa: Campos, Petrópolis e Niterói que abordavam o ensino de ofícios, e Paraíba do Sul que contava com aprendizagem agrícola (GARCIA, 2000). Posteriormente, em julho de 1909, com o falecimento do então Presidente do Brasil, Afonso Pena, Nilo Peçanha assume a Presidência e, pela experiência com a educação profissional adquirida durante o governo do Rio de Janeiro, em 23 de setembro de 1909 assina o Decreto n ${ }^{\circ} 7.566$, que permitiu a criação em diferentes unidades da federação, sob a jurisdição do Ministério dos Negócios da Agricultura, Indústria e Comércio, de dezenove instituições que denominou 
de Escolas de Aprendizes Artífices - EAA, destinadas ao ensino profissional, primário e gratuito. Entretanto, a educação profissional ofertada nestas escolas possuía um caráter assistencialista e/ou paternalista enfatizada em sua lei de criação, em seu artigo $6^{\circ}$, que respeitamos conforme a redação original:

Serão admittidos os individuos que o requererem dentro do prazo marcado para a matricula e que possuirem os seguintes requisitos, preferidos os desfavorecidos da fortuna: idade de 10 annos no minimo e de 13 annos no maximo; não soffrer o candidato molestia infecto-contagiosa, nem ter defeitos que o impossibilitem para o aprendizado de officio (BRASIL, 1909, Art. $6^{\circ}$ ).

Portanto, ao longo da história de nosso país, a Educação Profissional ou foi posta a serviço do capital ou possuía um caráter assistencialista e/ou paternalista e o público-alvo das EAA era considerado como desprovido de riqueza que, consequentemente, por essa condição, eram subalternos, desvinculados dos setores produtivos, e constituintes de um grupo urbano periférico que promove um obstáculo ao desenvolvimento nacional.

Com a diversificação da matriz produtiva, a partir dos anos 1930, temos a implantação de uma política de criação de novas escolas industriais e a criação de novas áreas de especialização das escolas já existentes. A constituição de 1937 é a primeira a contemplar em sua redação a criação de escolas voltadas aos ofícios, conforme estabelecia um de seus artigos:

É dever das indústrias e dos sindicatos econômicos criar, na esfera de sua especialidade, escolas de aprendizes, destinadas aos filhos de seus operários ou de seus associados. A lei regulará o cumprimento desse dever e os poderes que caberão ao Estado sobre essas escolas, bem como os auxílios, facilidades e subsídios a lhes serem concedidos pelo poder público (BRASIL, 1937 Art. No 129).

Antes mesmo da promulgação da nova constituição foi assinada, em 13 de janeiro daquele ano, a Lei $\mathrm{n}^{\mathbf{0}} 378$ que transformava as EAAs em Liceus Profissionais, que se destinavam ao ensino profissional, em diferentes ramos e graus. Em seguida temos a reforma de 1941, estabelecendo à educação profissional o grau de nível médio com os cursos divididos, primeiro em nível básico industrial e artesanal e segundo em técnico industrial, incluindo aí o estágio supervisionado. No ano de 1942 é promulgado um decreto que transformava os Liceus Profissionais em Escolas Industriais e Técnicas, sendo que seus alunos ficavam autorizados a ingressar no ensino superior equivalente, porém sem receber a formação básica adequada, limitando-os ao simples aprendizado das práticas. A partir de 1959 essas escolas são transformadas em autarquias, recebendo o nome de Escolas Técnicas Federais ou Escolas Agrotécnicas Federais e o objetivo nesse momento era a formação de profissionais que pudessem auxiliar no desenvolvimento do país tendo em vista o maciço investimento nas áreas de produção de energia e transporte do governo Juscelino Kubitschek. Em 1971, em uma catastrófica mudança de rumo, é instituído o ensino de segundo grau 
técnico-profissional e obrigatório, que em regime de urgência pretendia formar técnicos, mas que acabou por aprofundar o abismo intelectual existente na sociedade brasileira. Com essa distorção já corrigida, em 1978 temos o início da transformação das Escolas Técnicas Federais em Centros Federais de Educação Tecnológica, mas ainda mantendo o caráter formador de trabalhadores para o campo ou para as cidades industriais.

\section{A Educação Profissional e a formação crítica e social: a quebra do paradigma}

Somente com o sancionamento da lei $\mathrm{n}^{\circ}$ 9.394, de 20 de novembro de 1996, é que se tem a superação do enfoque assistencialista que as legislações anteriores insistiam em manter. O preconceito social onipresente até então é substituído por uma intervenção social crítica que favorece a inclusão e a democratização ao acesso às melhorias sociais. Nessa nova perspectiva para a educação profissional, temos a criação do Programa de Expansão da Educação Profissional em 1997 e a retomada da transformação das Escolas Técnicas Federais em Centros Federais de Educação Tecnológica a partir de 1999. Em 2004 é publicado o decreto $\mathrm{n}^{\circ}$ 5.154, em 23 de julho, permitindo que o ensino médio e o ensino técnico possam ocorrer de forma indissociável entre teoria e prática, estabelecendo de forma definitiva as bases necessárias à educação integradora.

A articulação entre a educação profissional técnica de nível médio e o ensino médio dar-se-á de forma: integrada, oferecida somente a quem já tenha concluído o ensino fundamental, sendo o curso planejado de modo a conduzir o aluno à habilitação profissional técnica de nível médio, na mesma instituição de ensino, contando com matrícula única para cada aluno. (BRASIL, 2004, Art. $4^{\circ} \S 1^{\circ}$ ).

Com esse decreto fica possibilitada a criação de instituições que possam oferecer ensino médio e profissional, permitindo, assim, a criação dos Institutos Federais, em 29 de dezembro de 2008, ao ser promulgada a lei $\mathrm{n}^{\circ} 11.892$ (BRASIL, 2008).

A partir de então tivemos uma grande expansão da Rede Federal e as 140 unidades de Centros Federais de Educação Profissional, agora transformados em Institutos, em menos de dez anos saltaram para 642 campi estruturados para a oferta de EPT. Toda a expansão foi acompanhada por forte investimento em estrutura, aparelhamento físico e de pessoal, permitindo uma oferta cada vez maior da Educação Profissional. Esse grande aumento de vagas na EPT fez com que se ampliasse exponencialmente a necessidade de professores de Química com formação na EPT, sendo que na lei de criação dos IFs está prevista a obrigatoriedade da oferta de licenciaturas nas áreas de Ciências voltadas para a educação profissional.

Observadas as finalidades e características definidas no art. $6^{\circ}$ desta Lei, são objetivos dos Institutos Federais: 
VI - ministrar em nível de educação superior:

b) cursos de licenciatura, bem como programas especiais de formação pedagógica, com vistas na formação de professores para a educação básica, sobretudo nas áreas de ciências e matemática, e para a educação profissional (BRASIL, 2008, art. $\left.7^{\circ}\right)$ - grifo nosso.

Com o dever de formar professores de Química com vista à educação profissional, os IFs necessitam de cursos de Licenciatura em Química que sejam capazes de preparar profissionais para essa modalidade de ensino.

\section{Projeto Pedagógico de Curso: documento base para a formação profissional}

O Projeto Pedagógico de um curso deve ser construído pensando, principalmente, na identidade formativa que se deseja ao egresso desse curso. A construção do projeto deve ocorrer por meio de uma ação coletiva, transparente e democrática efetuada pelos professores do curso, considerando as opções e escolhas de caminhos e prioridades na formação do profissional que se deseja sem deixar de considerar os aspectos ideológicos que se estabelecem. O PPC deve ter como proposta nortear a orientação e a condução do presente e do futuro de uma formação profissional, mantendo a conformidade com as Diretrizes Curriculares Nacionais estabelecidas pelo Ministério da Educação, e atender as demandas acadêmicas relacionadas às peculiaridades da formação do profissional desejado. Isso significa que a formulação dos PPCs deve considerar os aspectos envolvidos na articulação entre a teoria e a prática pedagógica e, para isso, deve estabelecer como o currículo do curso fará para romper com essa dualidade e como tal princípio educativo respalda a concepção de formação profissional. Os PPCs deverão ainda apontar para a identificação dos tipos de competências profissionais que se deve desenvolver nos profissionais em formação. E, finalmente, os PPCs devem prever uma matriz curricular ampla e flexível de forma a compreender os diferentes aspectos da atividade profissional do egresso.

Considerando atender aos aspectos enunciados acima de forma articulada com a oferta de EPT, consideramos que o PPC de um curso de Licenciatura em Química deverá conter no enunciado de seus objetivos a menção específica dessa modalidade de ensino. Além disso, a matriz curricular desse curso deverá ofertar ao menos uma disciplina voltada para a EPT, podendo nesse caso a disciplina ser dividida com outros aspectos da educação. Para que a matriz possa ser desenvolvida de forma completa, identifica-se a necessidade de existir uma base bibliográfica com no mínimo oito bibliografias específicas da EPT, pois entendemos que esse número é a base bibliográfica mínima exigida, para cada disciplina, na maioria dos PPCs. Pensando na articulação necessária entre a teoria e a prática, consideramos necessária a previsão de exercício regencial na EPT pelos estudantes do curso em algum momento de seu estágio supervisionado, podendo esse exercício, quando possível, ocorrer na própria instituição ofertante do curso de licenciatura. E finalmente entendemos que para a formação de um profissional preparado para atender as questões concernentes à EPT, os cursos de 
Licenciatura em Química devem prever em seus PPCs um perfil de egresso que abarca a atividade docente, gestora e pesquisadora na EPT.

\section{A questão do currículo em um Projeto Pedagógico de Curso}

Sacristán (2017) nos mostra que a concepção política, filosófica e econômica dos detentores do poder em uma sociedade se materializa no currículo. Isso ocorreria por meio de programas, metas, documentos oficiais, instâncias administrativas, entre outros. Essas questões dão origem ao que esse autor chama de currículo prescrito. Esse componente seria o responsável pela regulação educacional que poderia contribuir para a formação de uma cultura comum a todos os integrantes de uma sociedade. Seria o currículo prescrito que auxiliaria na construção dos mínimos curriculares regulados e isso favoreceria uma maior igualdade de oportunidades, desde que tivesse esse poder igualador devidamente analisado e normatizado por instrumentos adequados. Um Projeto Pedagógico de Curso de Licenciatura, por fazer parte do cabedal de documentos oficiais, poderia ser enquadrado como um componente do currículo prescrito principalmente se forem considerados os objetivos descritos nesse PPC. Porém, entendemos que no próprio PPC estariam outras manifestações do currículo.

Os materiais didáticos, como livros, apostilas, manuais, entre outros, são construídos observando o currículo prescrito. Porém, Sacristán (2017) argumenta se tratar de outro componente construtor do currículo, o que ele chamou de currículo apresentado ao professor. Nesse componente estariam incluídos esquemas de organização docente, equipes interdisciplinares, programas de formação, sistemas de controles, ambientes pedagógicos e outros mecanismos. Como nos PPCs é demonstrada a lista de bibliografias necessárias ao desenvolvimento do curso, podemos inferir que, nesse caso à maneira de Sacristán (2017), se trata do currículo apresentado ao professor. Isso também ocorreria no PPC quando da lista de disciplinas do curso, uma vez que as unidades disciplinares previstas em um projeto ficam disponibilizadas à execução também de atores diferentes de sua construção.

Apresentar um currículo não implica em executá-lo. O currículo modelado pelo professor, definido à maneira de Sacristán (2017), está originariamente subordinado a sua concepção pedagógica. O material utilizado no trabalho docente, ao ser efetuado, poderia proporcionar dicotomias a depender de seu executor, uma vez que o professor é um agente ativo sendo, portanto, sujeito e não objeto da prática educativa.

As tarefas escolares, os conteúdos de atividades práticas, as experimentações, as aplicações dos conhecimentos obtidos, o defrontar com a realidade, as descobertas mediadas e demais praxes utilizadas pelo professor são componentes do que Sacristán (2017) chamou de currículo na ação. Esse constituinte do currículo é impregnado de ações procedimentais, estando, portanto, atrelado à aplicabilidade dos conhecimentos obtidos no sistema educativo e isso depreenderia a ideia do estágio supervisionado que estaria descrito em um PPC.

Quando uma ação pedagógica resulta em efetiva aprendizagem de novos conhecimentos, costumamos dizer que o trabalho deu certo, isto é, o resultado foi obtido. Uma maneira de 
sabermos que isso realmente aconteceu é recorrermos a mecanismos avaliativos. No caso de um currículo, a maneira é semelhante. Sacristán (2017) argumenta que o processo de verificação do progresso dos alunos ao longo da escolaridade desenrolada por um determinado caminho educativo é o que poderia ser chamado de currículo avaliado. Como nos PPCs são apresentados o perfil do que se espera do egresso do curso, podemos admitir que aí se encontram indicações de uma possível avaliação da efetividade do curso em questão.

A ciência, a arte e a filosofia são dimensões do conhecimento que estabeleceriam, segundo Apple (2006), as bases necessárias ao currículo de forma a relacioná-lo com os interesses sociais de determinado tempo, lugar e cultura. Essas relações se concretizam, no nível escolar, por meio de ações desempenhadas pelos sujeitos da escola, do conteúdo escolhido e como é apresentado na atividade pedagógica. Portanto, uma lista de indicações bibliográficas e a proposição de uma determinada unidade curricular em um curso, seriam meios de materializar o currículo, ou seja, seria o currículo escrito, conforme alvitra o autor. Mas Apple (2001) alerta que os interesses de poder e de domínio econômico são capazes de interferir fortemente nas políticas educacionais que, principalmente por intermédio do currículo, inculcariam e internalizariam normas e valores da sociedade dominante. Esse seria o currículo oculto que Apple (2006) sinaliza como meio assegurador da manutenção da diretriz reinante. Mas as indicações desse autor não impedem que o currículo oculto possa ser construído dentro de um processo transformador social.

Giroux (1997) propõe que são possíveis intervenções e ações dentro de todo o aspecto escolar, e aí incluído o currículo, que poderiam subverter os propósitos do domínio hegemônico. Ele adverte que a vida em sociedade no geral e em específico o currículo, não são construídos apenas pelos detentores da dominação, mas que existe a possibilidade de resistir, de se contrapor à conjuntura do poder e de perturbar a ordem estabelecida. Ele se fundamenta no conceito de resistência e admite que os dominados não estão totalmente alijados da cultura dos dominantes e que o caráter revolucionário é capaz de fluir em suas ideias, em seus verbos e atitudes. No âmbito educacional, para Giroux, cabe ao professor e seus estudantes a missão revolucionária de transformação social, que não poderia vir a cabo sem que trespassasse pelas alterações do currículo.

Como a construção do Projeto Pedagógico de um curso de licenciatura é de responsabilidade da escola e deverá ser executado pelos seus professores, possível ator transformador social, conforme salienta Giroux (1997), esse importante componente do currículo prescrito, em concordância aos preceitos de Sacristán (2017), poderá estar livre de condicionantes políticos oficiais, ficando à mercê do ideário docente, que poderia determinar um currículo oculto, ao modo de Apple (2006). É aqui que poderemos nos aproximar da construção de um currículo de caráter revolucionário conforme proposto por Giroux (1997), utilizar de forma adequada as ideias que julgamos importantes do pensamento político, social, filosófico, econômico apontado por Apple (2006) e é nesse ponto que consideramos que o currículo prescrito se aproximaria do currículo apresentado ao professor e do modelado pelo professor, conforme sugere Sacristán (2017). 


\section{Procedimentos Metodológicos}

Procurando verificar se as bases legais construídas para a oferta de EPT, nos cursos de Licenciatura em Química ofertados dentro nos IFs, estão sendo consideradas, nos fizemos valer de uma pesquisa de abordagem qualitativa, uma vez que pretendemos dar valor aos textos analisados e as pesquisas quantitativas costumam apresentar dificuldades no esclarecimento do emaranhado de relações internas próprias do universo educacional (LÜDKE e ANDRÉ, 1986). Diferentemente de grande parte dos estudos quantitativos, os estudos qualitativos, como o que apresentamos aqui, não exigem que a perspicuidade sobre as perguntas de pesquisa e as hipóteses sejam elaboradas antes da coleta e da análise dos dados. Nas pesquisas com enfoque qualitativo é possível desenvolver perguntas, bem como elaborar hipóteses a qualquer momento da atividade de pesquisa. Os eventos investigados e o olhar crítico dado sobre eles se interligam de maneira tal que permitem o constante aprimoramento da pergunta que se pretende responder com a investigação (SAMPIERI, et al., 2013). No caso de nossa pesquisa, é exatamente isso que ocorreu, o que nos leva a descrever o conjunto de ações e estratégias que nos auxiliaram na obtenção dos dados.

O desenho, assim como a amostra, a coleta dos dados e a análise vão surgindo desde a formulação do problema até a imersão inicial e o trabalho de campo e, claro, passando por modificações, mesmo que seja mais uma forma de enfocar o fenômeno de interesse (SAMPIERI, at al., 2013, p. 497).

Objetivando uma análise descritiva do estudo desenvolvido e objetivando evitar distorções oriundas da temporalidade, recortamos nossa investigação analisando PPCs construídos entre os anos de 2008 e 2016, considerando que os IFs foram instituídos a partir de 2008, o que isentaria os PPCs anteriores a essa data de conter aspectos da EPT. Foram analisados todos os PPCs dos cursos de Licenciatura em Química dos IFs disponíveis na internet, totalizando 52 projetos. Porém, 4 deles foram descartados devido a sua construção ter ocorrido em data anterior à criação dos IFs.

Optamos por desenvolver uma análise documental, que é uma técnica largamente utilizada em pesquisas na educação e, segundo Lüdke (1986), ela pode fazer inferências sobre, entre outras coisas, intensões e ideologia dos autores do documento tendo como referência a presença de determinadas palavras, termos ou conceitos que traduzam posicionamentos políticos e ideológicos. Ao identificarmos a presença desses termos nos textos dos PPCs, os separamos em três diferentes categorias de análise: a dos aspectos explícitos de abordagem, quando a presença da EPT era facilmente percebida e as intenções relativas à investigação da EPT estavam claras; os aspectos relativos de abordagem, nesse caso quando a EPT poderia se fazer presente de forma velada - como na historicidade da educação, na simples leitura de leis ou aparecer apenas em disciplinas optativas, o que nesse caso não caracterizaria a abrangência da EPT para todos os discentes do curso; e não aborda, no caso da EPT não aparecer no texto do PPC. 
As análises dos PPCs foram feitas considerando cinco quesitos diferentes. Procuramos investigar se os PPCs de Licenciatura em Química nos IFs estão estruturados de forma a abordar a EPT em seus objetivos, uma vez que isso seria um primeiro indicativo da preocupação do curso com a formação de profissionais para essa modalidade de ensino. Constatada a presença da EPT em seus objetivos, seria de se esperar que o curso previsse disciplinas que tratariam dessa questão, por esse motivo investigamos, também, todas as matrizes curriculares dos projetos analisados. Existindo disciplina na matriz curricular, necessariamente teríamos que ter uma previsão bibliográfica mínima voltada para a EPT, e esse foi o motivador de analisarmos toda a oferta de livros prevista nos Projetos. Em seguida, analisamos nos PPCs os pressupostos metodológicos para o estágio supervisionado levando em consideração a previsão de intervenção do estagiário nessa modalidade de ensino. E por último verificamos se as propostas formativas previstas para o perfil do egresso desses cursos consideravam a EPT como parte da formação do profissional que se deseja.

Um caso que poderia exemplificar a nossa opção de categorização dos textos dos PPCs, seria o do curso de Licenciatura em Química do IFB campus Gama que, em seus objetivos, pretende:

Contribuir para a melhoria da Educação Básica e da Educação profissional através do desenvolvimento de competências próprias à atividade docente, que ultrapassem o conhecimento científico e avancem para a formação de competências profissionais de caráter pedagógico, referentes ao conhecimento de processos de investigação e reflexão sobre a prática cotidiana; (IFB, 2014, pag. 9) - grifo nosso.

Como nesse item aparece a intencionalidade de contribuir com a "educação profissional", os objetivos desse PPC foram enquadrados na categoria 'aspectos explícitos de abordagem'. Porém, quando analisamos o perfil do egresso descrito nesse PPC não foi encontrada referência à EPT, isso nos fez enquadrar esse perfil na categoria 'não aborda'. A presença de componente curricular obrigatório que trata da EPT foi categorizada como de abordagem relativa, já que não possui uma disciplina própria para as questões da EPT mas traz a disciplina Estrutura e Funcionamento da Educação Brasileira, com carga horária de 80h, que prevê a EPT no desenvolvimento de habilidade do licenciando - estudar a estrutura e o funcionamento da Educação Técnica e Profissionalizante no Brasil (IFB, 2014, pag. 24) - e relaciona a EPT como uma base tecnológica, uma vez que considera em seu texto

A Educação Básica e o Ensino Superior, bem como a Educação Profissional, no contexto da educação nacional: sua organização e funcionamento (IFB, 2014, pag. 24).

A lista de bibliografia recomendada nesse PPC possui apenas um livro em que é possível a abordagem da EPT - trata-se da obra Pedagogia Histórico-Crítica, de Dermeval Saviani, em que a politecnia é discutida - o que nos fez categorizarmos a bibliografia desse PPC como de 'aspectos relativos de abordagem'. Como o texto do PPC não traz previsão de regência 
em estágio supervisionado na EPT, isso nos fez enquadrar o seu estágio na categoria 'não aborda'.

\section{Resultados e Discussão}

Como os IFs foram instituídos a partir de 2008, dos 52 PPCs analisados, somente 4 são de construção anterior à criação dos IFs e, por esse motivo, não entraram na formulação dos resultados de nossa pesquisa. Porém, ainda considerando a temporalidade dos PPCs, é importante observar que 34 deles foram produzidos nos últimos 4 anos e, portanto, estariam mais expostos às modernidades e transformações da educação brasileira. Os resultados das análises mostram que, apesar dessa construção recente, na maioria dos PPCs as questões que envolvem a EPT não foram encontradas, evidenciando que mesmo projetos recentes não estão voltados para as necessidades da EPT.

Os objetivos de um curso deveriam apontar, em longo prazo, o alcance e a intencionalidade das propostas da formação, focando na peculiaridade do profissional que se deseja e, no caso dessa investigação, o foco seria a aquisição de competências para a prática da EPT. Na análise de seus objetivos, apenas quatro PPCs contemplam explicitamente a EPT, conforme podemos observar no texto a seguir retirado de um desses projetos.

Oferecer aos licenciados em Química ampla formação teórica e prática, integrando as dimensões específicas e pedagógicas da atuação docente, voltada para a educação básica (ensino fundamental - anos finais - e ensino médio) e educação profissional e tecnológica. (IFFarropilha, 2015, p. 16). Grifo nosso.

Os demais quarenta e quatro projetos pedagógicos não abordam essa modalidade de ensino, não prevendo nem mesmo a EPT de forma relativa em seus objetivos.

O aparecimento de disciplinas como Fundamentos da Educação Profissional, Educação Profissional e Educação de Jovens e Adultos e Prática de Ensino na Educação Profissional foi observada e consideramos como 'aspectos explícitos de abordagem'. Essa questão aparece em apenas seis projetos, sendo que em três deles há a ocorrência de duas disciplinas que abordam a EPT e nos outros apenas uma disciplina. Em dezoito projetos a EPT é tratada em disciplinas de história da educação ou correlata, muitas vezes aparecendo apenas uma breve menção à EPT e em outros três projetos a EPT aparece como disciplina optativa - por isso essas abordagens foram consideradas como 'abordagem relativa'. Nos demais PPCs analisados, a EPT não é tratada em disciplina curricular. Esses números são de melhor compreensão se observarmos o segundo conjunto de colunas mostrados no gráfico 1.

Em apenas dezoito dos quarenta e oito cursos de Licenciatura em Química investigados por meio da análise de seus PPCs existe a previsão de bibliografia voltada para a investigação da EPT, porém em só seis desses projetos a bibliografia indica oito ou mais livros. Em seis deles existe a previsão de somente um livro, em três projetos a previsão é de dois livros, um dos projetos prevê quatro livros, em outro cinco livros e em outro desses projetos a previsão 
é de seis livros voltados à EPT. Categorizamos os projetos que apresentam oito ou mais livros previstos para a bibliografia da EPT como de abordagem explícita e os que apresentam livros em número inferior a oito como de abordagem relativa. Esses números podem ser observados no terceiro conjunto de colunas mostrados no gráfico 1. Na análise desses livros consideramos todas as bibliografias, de disciplinas obrigatórias, que abordam a Educação Profissional, as que investigam a relação da educação e o trabalho e os que consideram a questões relativas a Ciências, Tecnologia e Sociedade.

A prática como componente curricular é obrigatória nos cursos de licenciaturas (MEC, 2011) e é caracterizada por meio das atividades que proporcionam experiências de aplicação dos conhecimentos adquiridos na formação ou no desenvolvimento de procedimentos próprios ao exercício de ações previstas para o licenciado. Por meio dessas atividades, o licenciando pode pôr em uso os conhecimentos, as competências e as habilidades adquiridas nas diferentes atividades formativas presentes em seu currículo. Pensando na necessidade de formação de docentes que possuam competências para o exercício de atividades na EPT, investigamos se os PPCs dos cursos de Licenciatura em Química dos IFs estão contemplando a possibilidade de desenvolvimento de atividades de estágio supervisionado nessa modalidade de ensino. Dos cursos analisados, em apenas seis temos a previsão de execução do estágio na EPT. Porém, somente em três temos essa questão de forma obrigatória; em dois dos projetos existe a possibilidade do desenvolvimento na EPT e em outro projeto a EPT está prevista apenas nas atividades de observação do estagiário. Essa análise é mostrada por meio do quarto conjunto de colunas do gráfico 1. Podemos exemplificar a abordagem explícita da EPT no estágio supervisionado pelo texto retirado de um dos PPCs analisados que mostramos a seguir.

O Estágio deverá ser realizado pelo aluno, sob o acompanhamento docente, nas instituições de educação básica mantidas pela rede pública de ensino, bem como em instituições de educação profissional e tecnológica que ofertem a educação profissional integrada à educação básica (CEFET Goiás, 2008).

Um indivíduo pode ser considerado competente quando, diante de uma situaçãoproblema, for capaz de selecionar, organizar e mobilizar, na ação, diferentes recursos que possibilitem o enfrentamento da problemática posta. A formação de licenciandos em química que possuam habilidades e competências para o exercício da EPT deve estar prevista no perfil dos egressos desses cursos e listadas em seus PPCs. Uma exemplificação de 'abordagem explícita' da EPT no perfil do egresso, caracterizada por nós, pode ser observada no texto que mostramos a seguir.

O curso de Licenciatura em Química, em seus diferentes momentos, irá propiciar aos alunos oportunidades de vivenciarem situações de aprendizagem de maneira a construir um perfil profissional adequado à formação de professores para a educação básica, e também compatível com a possibilidade de atuação na educação profissional, principalmente no caso do ensino médio integrado,... (IFNMG, 2010., pag. 15) - grifo nosso. 
Ainda considerando essa questão foi possível observar que somente três PPCs trazem na listagem de habilidades e competências desejadas aos formandos a preparação para a EPT, sendo que em um deles ocorre uma abordagem apenas superficial, pois reconhece a necessidade da formar licenciados capazes de integrar os conhecimentos de química com as atividades técnicas e de produção, não considerando a EPT como atividade profissional. Toda essa questão pode ser compreendida observando o quinto conjunto de colunas mostrado no gráfico 1.

Gráfico 1: Apresentação dos quesitos analisados nos PPCs em comparação com a frequência dos tipos de abordagens.

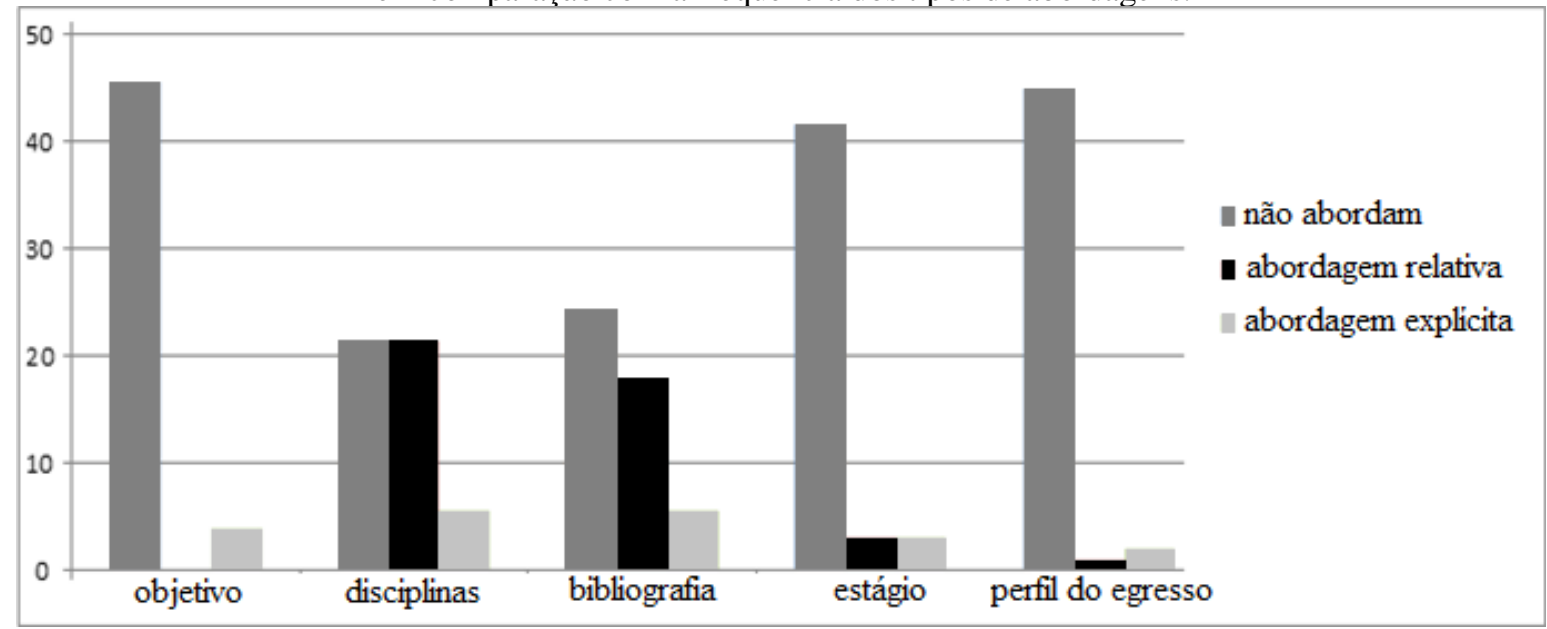

Fonte: Produzido pelos autores.

\section{Considerações Finais}

Apesar de a Educação Profissional estar em franca expansão em nosso país e seu principal articulador serem os Institutos Federais, criados em 2008 sob a obrigatoriedade de também preparar profissionais para a EPT, os seus cursos de Licenciatura em Química, em sua maioria, não objetivam essa modalidade de ensino, considerando que apenas quatro desses cursos estão prevendo a EPT em seus objetivos. Como parte significativa dos cursos analisados não oferece disciplinas para que as prerrogativas concernentes à EPT possam ser discutidas e a maioria das que oferecem o fazem de forma velada sem que a EPT tenha protagonismo, é perceptível a falta de abordagem teórica dos pressupostos da EPT nesses cursos. O fato dos PPCs negligenciarem as discussões teóricas da EPT está também demonstrado por meio da total ausência ou da pouca presença efetiva de bibliografias que discutem a EPT. Os PPCs, em sua grande maioria, não observam as instituições ofertantes de EPT como possibilidade de regência para estagiários, não se preocupando com a articulação dos pressupostos teóricos e práticos da EPT e ignorando a devida preparação de 
profissionais voltados para o trabalho na EPT sem ao menos prever, em seus egressos, a possibilidade de desenvolvimento de habilidades e competências específicas dessa modalidade de ensino

As análises dos objetivos, da oferta de disciplinas, da lista bibliográfica, das possibilidades de estágio supervisionado e do perfil do egresso nos PPCs dos cursos de licenciatura em Química dos IFs, formam um conjunto de dados isolados que, quando verificados em conjunto, passam a se mostrar como um forte indicativo de que a EPT, apesar de ter suas vagas em franca expansão, não está sendo considerada na imensa maioria dos cursos de licenciatura em Química existentes nos IFs. E em nenhum desses cursos observamos a presença de todos os quesitos analisados de forma simultânea, o que demonstra que a preocupação com a EPT, quando existente nos cursos, não se dá de forma completa.

Os Institutos Federais foram criados com a obrigatoriedade de ofertar cursos de licenciatura de forma a preparar docentes para atividades na Educação Profissional e Tecnológica (EPT). Para essa oferta, tem-se a necessidade de criação de Projeto Pedagógico de Curso (PPC), que abarca essa modalidade de ensino dentro do cabedal metodológico, pedagógico e teórico da EPT. Analisamos PPCs de Licenciatura em Química para verificar os possíveis enfoques dados à EPT e os resultados obtidos apontam para a inexistência de enfoques à EPT nos PPCs de cursos de Licenciatura em Química, indicando que, se considerarmos os PPCs, os Institutos Federais não estão cumprindo com uma parte dos deveres estabelecidos em lei.

Construir Projetos Pedagógicos de Cursos de Licenciatura em Química que considerem a Educação Profissional como parte importante na formação para o trabalho colaboraria para a elaboração de um importante documento, parte de um currículo prescrito, que poderia estimular a EPT em nosso país. Consideramos importante para isso que a EPT esteja presente no objetivo do curso, no perfil do egresso, que tenha ao menos um componente curricular obrigatório, que na lista bibliográfica apareçam livros voltados à EPT e que essa modalidade esteja prevista como atividade no estágio supervisionado obrigatório.

\section{Referências}

APPLE, M. W. Reestruturação Educativa e Curricular e as agendas neoliberal e neoconservadora: entrevista com Michael Apple. Currículo sem Fronteiras, v.1, n.1, 2001, p. 5-33.

Ideologia e Currículo. $3^{\mathrm{a}}$ edição. Porto Alegre: Artmed, 2006.

BIELINSKI, A. C. O Liceu de Artes e Ofícios - sua história de 1856 a 1906. Revista 19 \& 20, Rio de Janeiro, v. IV, n. 1, jan. 2009.

BRASIL. Constituição dos Estados Unidos do Brasil, de 10 de novembro de 1937. Disponível em: <http://www.planalto.gov.br/ccivil_03/Constituicao/Constituicao37.htm> acesso em 18/08/2018

Decreto-lei $n^{\circ} 7.566$ de 23 de setembro de 1909. Crêa nas capitaes dos Estados da Republica Escolas de Aprendizes Artifices, para o ensino profissional primario e gratuito. Disponível em: 
<http://www2.camara.leg.br/legin/fed/decret/1900-1909/decreto-7566-23-setembro-1909-525411publicacaooriginal-1-pe.html> acesso em 19/08/2018.

Decreto $n^{\circ} 5.154$ de 23 de julho de 2004. Regulamenta o $\S 2^{\circ}$ do art. 36 e os arts. 39 a 41 da Lei $n^{\circ}$ 9.394, de 20 de dezembro de 1996, que estabelece as diretrizes e bases da educação nacional, e dá outras providências. Disponível em: <http://www.planalto.gov.br/ccivil_03/_ato20042006/2004/decreto/d5154.htm> acesso em 19/08/2018.

Lei $n^{\circ} 11.892$, de 29 de dezembro de 2008. Institui a Rede Federal de Educação Profissional, Científica e Tecnológica, cria os Institutos Federais de Educação, Ciência e Tecnologia, e dá outras providências. Disponível em: <http://www.planalto.gov.br/ccivil_03/_ato2007-2010/2008/lei/111892.htm> acesso em 19/08/2018.

CEFET Goiás. Projeto Pedagógico do Curso de Licenciatura em Química. Centro Federal de Educação Tecnológica de Goiás campus Itumbiara, GO. 2008.

FONSECA, C. S. História do Ensino Industrial no Brasil. Rio de janeiro: Escola Técnica, 1961.

GARCIA, S. R. de O. O fio da história: a gênese da formação profissional no Brasil. In: Trabalho e Crítica. São Leopoldo: Ed. UNISINOS, 2000.

GIROUX, H. A. Professores como intelectuais Transformadores Os professores como intelectuais: rumo a uma pedagogia crítica da aprendizagem. Porto Alegre: Artes Médicas, 1997.

IFB. Projeto Pedagógico de Curso - Licenciatura em Química. Instituto Federal Brasília campus Gama. Brasília, DF 2014.

IFFarropilha. Projeto Pedagógico do Curso Superior de Licenciatura em Química. Instituto Federal Farroupilha campus Alegrete. Alegrete, RS. 2015.

IFNMG. Projeto Pedagógico Licenciatura em Química. Instituto Federal do Norte de Minas Gerais campus Salinas. MG. 2010.

LUDKE, M.; ANDRÉ, M. E.D.A. Pesquisa em educação: abordagens qualitativas. São Paulo, Editora Pedagógica e Universitária, 1986. 99p.

MANFREDI, S. M. Educação Profissional no Brasil. São Paulo: Cortez, 2002.

MARTINS, A. C. P. Ensino superior no Brasil: da descoberta aos dias atuais. Revista Acta Cirurgica Brasileira. vol.17 supl.3 São Paulo 2002.

MEC 2011. Diretrizes Curriculares Nacionais Disponível em: <http://portal.mec.gov.br/index.php?option= com_content\&view=article\&id=12991> acesso em 23/07/2017.

SACRISTÁN, J. G. O currículo: uma reflexão sobre a prática; tradução: Ernani F. da Fonseca rosa; $3^{\mathrm{a}}$ edição. Porto Alegre: Penso, 2017.

SAMPIERI, R. H.; COLlADO, C. F.; LUCIO, M. P. B. Metodologia de pesquisa. $5^{\text {a }}$ edição, Porto Alegre: McGraw Hill, 2013. 


\section{Correspondência}

Alexandre Geraldo Viana Faria: É graduado em Licenciatura em Química pela Universidade Federal de Mato Grosso do Sul (2006). Mestre em Ensino de Ciências (PPEC) pela Universidade Federal de Mato Grosso do Sul na área de concentração em Ensino de Química. Professor EBTT do Instituto Federal de Educação, Ciência e Tecnologia de Mato Grosso do Sul.

E-mail: alexandre.faria@ifms.edu.br

Maria Celina Piazza Recena: É graduada em Química pela Universidade Federal do Rio Grande do Sul (1979), mestre em Educação pela Universidade Federal de Santa Catarina (1990) e doutora em Ciências da Saúde pela Universidade de Brasília (2005). Professora titular, aposentada e com vínculo como voluntária atuando nos mestrados de Ensino de Ciências e de Saúde da Família, bem como no doutorado em Ensino de Ciências e Educação Ambiental, da UFMS.

E-mail: mcrecena@yahoo.com.br

Texto publicado em Currículo sem Fronteiras com autorização dos autores 